\title{
The Intertemporal State Adjustment Model
}

\author{
Michael K. Wohlgenant \\ Department of Agricultural \& Resource Economics, North Carolina State University, Raleigh, NC, USA \\ Email: michaelwhlgnnt@gmail.com
}

How to cite this paper: Wohlgenant, M.K. (2017) The Intertemporal State Adjustment Model. Theoretical Economics Letters, 7, 582-588.

https://doi.org/10.4236/tel.2017.73043

Received: March 10, 2017

Accepted: April 21, 2017

Published: April 24, 2017

Copyright (c) 2017 by author and Scientific Research Publishing Inc. This work is licensed under the Creative Commons Attribution International License (CC BY 4.0).

http://creativecommons.org/licenses/by/4.0/

\begin{abstract}
The implications of the intertemporal state adjustment model (ISAM) are evaluated. The ISAM accounts for the effect of current purchases on future utility through a state variable that can either reflect habit formation or inventory holding. The model is shown to be forward looking with purchases depending upon beginning-of-the period state variable as well as the present discounted value of future user costs of the state variable. In this way, the model accounts for the speculative motive for inventory holding. The myopic state adjustment model, which depends on the beginning-of-the period state variable and current price, is a special case of ISAM when the discount rate is zero. Other special cases of the ISAM are identified and alternative representations of it for empirical analysis are presented.
\end{abstract}

\section{Keywords}

State Adjustment Model, Consumer Inventory Behavior, Intertemporal Consumer Choice

\section{Introduction}

There is a large literature on inventories and consumer behavior, but virtually all studies assume utility depends only on consumption and not beginning-of theperiod inventories ${ }^{1}$. Making the current period utility function dependent on inventories is in the spirit of the classic approach of Houthakker and Taylor [2] and Phlips [3], who developed empirically tractable models that allowed one to investigate whether demand exhibits habit formation or durable demand. Their modeling approach specified utility as a function of both purchases of the good and a state variable. If the state variable exhibits habit formation, then the marginal utility of consumption would increase as the state variable increases; on the other hand, if the state variable exhibits predominately durable behavior then the marginal utility of consumption would decrease as the state variable increa-

${ }^{1}$ See, for example, Hendel and Nevo [1] for an up-dated review. 
ses.

The main problem with the myopic state adjustment model is that it does not account for the speculative motive for inventory holding. In particular, no provision is made for the influence of anticipated capital gains (losses) from holding the stock. Moreover, if the consumer is forward looking, he will take into account the effect of purchases on future marginal utility. Also with inventory behavior, consumer purchases can differ from consumption. Thus, an intertemporal version of the state adjustment model is necessary to accommodate these features and to extend the myopic state adjustment model to a model amenable to empirical specification and analysis. The purpose of this note is to extend the model to its intertemporal version and show how it accounts for both demand with habit formation and stock holding.

\section{The Model}

The consumer is assumed to maximize the present discounted value of future utility subject to an intertemporal budget constraint and the equation of motion defining how inventories change over time. The utility function for period $t$ is

$$
v\left(q_{t}, s_{t}\right)+\varphi\left(y_{t}\right)
$$

where $q_{t}$ is purchases of the good in question, $s_{t}$ is the level of the state variable at the beginning of time $t$, and $y_{t}$ is the quantity of the composite good of all other goods purchased. We assume that the utility function is strongly separable with respect to choice of the good and the composite good. The state variable is assumed to change over time according to the relationship:

$$
s_{t+1}-s_{t}=q_{t}-\delta s_{t}
$$

where the parameter $\delta$ is the (assumed) constant rate of depreciation of the state variable. If the state variable on net reflects habit formation, the parameter shows how the stock of habits depreciates with respect to time; if the state variable reflects durability of the product, then the parameter shows the rate of depreciation of the asset over time. For a commodity that is storable, the parameter can be interpreted as the rate of consumption per time period. Finally, the budget constraint is

$$
w_{t}=\sum_{j=t}^{T} \beta^{j-t}\left(p_{j} q_{j}+y_{j}\right)
$$

where $w_{t}$ is the present discounted of wealth at time $t, \beta$ is the one period discount rate, and $p_{j}$ is price of the good, with the price of the composite good taken to be unity ${ }^{2}$.

The Lagrangian function for maximizing utility subject to the budget constraint is

$$
L=\sum_{j=t}^{T} \beta^{j-t}\left[v\left(q_{j}, s_{j}\right)+\varphi\left(y_{j}\right)-\lambda\left(p_{j} q_{j}+y_{j}\right)-\mu_{j}\left(s_{j+1}-(1-\delta) s_{j}-q_{j}\right)\right]+\lambda w_{t}
$$

The first-order conditions are:

${ }^{2}$ Chaloupka [4] develops a similar model but his focus is only on habit formation for cigarettes. 


$$
\begin{gathered}
\frac{\partial L}{\partial q_{t}}=\frac{\partial v\left(q_{t}, s_{t}\right)}{\partial q_{t}}-\lambda p_{t}+\mu_{t}=0 \\
\frac{\partial L}{\partial y_{t}}=\frac{\mathrm{d} \varphi\left(y_{t}\right)}{\mathrm{d} y_{t}}-\lambda=0 \\
\frac{\partial L}{\partial s_{t+1}}=\beta \frac{\partial v\left(c_{t+1}, s_{t+1}\right)}{\partial s_{t+1}}-\mu_{t}+\beta(1-\delta) \mu_{t+1}=0 \\
\frac{\partial L}{\partial \lambda}=-\sum_{j=t}^{T} \beta^{j-t}\left(p_{j} q_{j}+y_{j}\right)+w_{t}=0 \\
\frac{\partial L}{\partial \mu_{t}}=-s_{t+1}+(1-\delta) s_{t}+q_{t}=0
\end{gathered}
$$

Following Becker et al [5], assume that the consumer takes the marginal utility of wealth, $\lambda$, as constant ${ }^{3}$. With $\lambda$ taken as constant, we can substitute (1) into (3) and use (5) to obtain:

$$
\begin{aligned}
& \beta v_{s}\left(s_{t+2}-(1-\delta) s_{t+1}, s_{t+1}\right)-\beta(1-\delta) v_{q}\left(-(1-\delta) s_{t+1}, s_{t+1}\right) \\
& +v_{q}\left(s_{t+1}-(1-\delta) s_{t}, s_{t}\right)=\lambda p_{t}-\beta(1-\delta) \lambda p_{t+1}
\end{aligned}
$$

where subscripts denote first-order partial derivatives.

The comparative statics of this relationship can be ascertained through differentiating the first-order conditions (6). For simplicity, assume the utility function is quadratic:

$$
u_{t}=0.5 v_{q q} q_{t}^{2}+0.5 v_{s s} s_{t}^{2}+v_{q s} q_{t} s_{t}+0.5 y_{t}^{2}
$$

where for convenience the linear terms (which produce constant derivatives) have been omitted. Taking derivatives of (7), substituting into (6), and combining like terms in $s_{t}$ results in the expression:

$$
\begin{aligned}
& \beta\left(v_{q s}-(1-\delta) v_{q q}\right) s_{t+2}+\left[\beta \delta v_{s s}+\beta\left((1-\delta)^{2}+1\right) v_{q q}-2 \beta(1-\delta) v_{q s}\right] s_{t+1} \\
& +\left(v_{q s}-(1-\delta) v_{q q}\right) s_{t}=\lambda p_{t}-\beta(1-\delta) \lambda p_{t+1}
\end{aligned}
$$

The solution in terms of $s_{t+1}$ is:

$$
s_{t+1}=\theta s_{t}+\beta \theta s_{t+2}+\theta_{1}\left[\lambda p_{t}-\beta(1-\delta) \lambda p_{t+1}\right]
$$

where $\theta_{1}=\left[\beta \delta v_{s s}+\beta\left((1-\delta)^{2}+1\right) v_{q q}-2 \beta(1-\delta) v_{q s}\right]^{-1}$ and $\theta=\theta_{1}\left[(1-\delta) v_{q q}-v_{q s} d\right]$. The parameter $\theta_{1}$ is expected to be negative due to the fact that the utility function is strictly concave. The parameter $\theta$ will be positive if $v_{q s}>0$, which is what we would expect if habit formation dominates. On the other hand, if durable good behavior dominates, $v_{q s}<0$, and $\theta<0$ if $\left|v_{q s}\right|>\left|(1-\delta) v_{q q}\right|$, which is more likely the larger the depreciation rate $\delta$.

Upon substituting Equation (9) into Equation (5) we obtain the demand equation for the good in question:

${ }^{3}$ Alternatively, if good accounts for small share of total expenditures, one could substitute the solution for $y_{t}$ from first-order condition (2) for $\lambda$ into the equations. Either way, $\lambda$ may be taken as exogenous. 


$$
q_{t}=-[(1-\delta)-\theta] s_{t}+\beta \theta s_{t+2}+\theta_{1}\left[\lambda p_{t}-\beta(1-\delta) \lambda p_{t+1}\right]
$$

Demand for the good depends upon the level of state variable at the beginning of the time period, the level of state variable at the end of period $t+1\left(s_{t+2}\right)$, and the user-cost of the state variable, $\lambda p_{t}-\beta(1-\delta) \lambda p_{t+1}{ }^{4}$.

\section{Evaluation of the Model}

\section{Proposition 1.}

The solution to the second-order state adjustment Equation (9) is stable and has the form (provided $\lambda p_{t}-\beta(1-\delta) \lambda p_{t+1}$ does not grow at a rate larger than $\left.\left|\lambda_{2}^{-1}\right|\right):$

$$
s_{t+1}=\left(1-\lambda_{1}\right) s_{t}+\frac{\theta_{1}}{\beta \theta \lambda_{2}} \sum_{j=0}^{\infty} \lambda_{2}^{-j}\left(\lambda p_{t+j}-\beta(1-\delta) \lambda p_{t+1+j}\right)
$$

where for $\theta>0,0<\lambda_{1}<1$, and $\lambda_{2}>1$; for $\theta<0,-1<\lambda_{1}<0$, and $\lambda_{2}<-1$.

Proof:

Rewrite (9) as follows:

$$
\left(1-\beta^{-1} \theta^{-1} L+\beta^{-1} L^{2}\right) L^{-1} s_{t+1}=-\beta^{-1} \theta^{-1} \theta_{1} z_{t}
$$

where $L$ is the lag operator and $z_{t}=\lambda p_{t}-\beta(1-\delta) \lambda p_{t+1}$. Obtain the factorization,

$$
\left(1-\lambda_{1} L\right)\left(1-\lambda_{2} L\right)=\left(1-\beta^{-1} \theta^{-1} L+\beta^{-1} L^{2}\right)
$$

implying that $\lambda_{1}+\lambda_{2}=\beta^{-1} \theta^{-1}$ and $\lambda_{1} \lambda_{2}=\beta^{-1}$. The characteristic equation is

$$
\lambda^{2}-\beta^{-1} \theta^{-1} \lambda+\beta^{-1}=0
$$

The solution to the characteristic equation is

$$
\lambda_{1}, \lambda_{2}=\frac{\beta^{-1} \theta^{-1 \pm}\left(\beta^{-2} \theta^{-2}-4 \beta^{-1}\right)^{0.5}}{2}
$$

The roots of this equation are real [6]. There are two possible values for the roots: i) if $\theta>0$, then $0<\lambda_{1}<1$ and $\lambda_{2}=\beta^{-1} \lambda_{1}^{-1}>1$; ii) if $\theta<0$, then $-1<\lambda_{1}<0$ and $\lambda_{2}<-1$. Note that $\left(1-\lambda_{2}\right) L^{-1}=-\left(1-\lambda_{2}^{-1} L^{-1}\right) \lambda_{2}$. Upon substituting for (13), rearranging terms, and substituting into (12) we obtain

$$
-\left(1-\lambda_{2}^{-1} L^{-1}\right)\left(1-\lambda_{1} L\right) \lambda_{2} s_{t+1}=-\beta^{-1} \theta^{-1} \theta_{1} z_{t}
$$

Multiplying through both sides by $-\lambda_{2}^{-1}$ and $\left(1-\lambda_{2}^{-1} L^{-1}\right)^{-1}$, and substituting for $Z_{t}$ yields the desired result.

\section{Proposition 2.}

The intertemporal state adjustment model is:

$$
q_{t}=-\left[(1-\delta)-\theta\left(1-\left(1-\lambda_{1}\right)\right) \beta\right] s_{t}++\frac{\theta_{1}}{\lambda_{2}} \sum_{j=0}^{\infty} \lambda_{2}^{-j}\left(\lambda p_{t+j}-\beta(1-\delta) \lambda p_{t+1+j}\right)
$$

${ }^{4}$ To see that $\lambda p_{t}-\beta(1-\delta) \lambda p_{t+1}$ can be interpreted as the user-cost of capital, note that $\beta=1 /(1+r)$, where $r$ is the one-period discount rate. Substituting for $\beta$ in the above expression and expressing it in the same denominator we obtain: $\beta\left[(r+\delta) \lambda p_{t}-(1-\delta)\left(\lambda p_{t+1}-\lambda p_{t}\right)\right]$. Thus, $\lambda p_{t}-\beta(1-\delta) \lambda p_{t+1}$ can be thought of as the discounted sum of interest and depreciation expense less any capital gains from holding the stock. 


\section{Proof:}

Substitute Equation (11) into Equation (5) and combine like terms to obtain result.

\section{Proposition 3.}

The myopic, static state adjustment model

$$
q_{t}=\theta s_{t}+\theta_{1} \lambda p_{t}
$$

results as a special case of the intertemporal adjustment model, Equation (14), if the discount rate $\beta=0$.

\section{Proof:}

Using Equation (5) in Equation (6) with the quadratic utility function (7) when $\beta=0$ yields the desired result for $\theta=-\frac{v_{q s}}{v_{q q}}$.

Another special case of the intertemporal model can be isolated when the depreciation rate $\delta=1$.

\section{Proposition 4.}

The intertemporal state adjustment model with $\delta=1$ becomes

$$
q_{t}=\beta \theta\left[1-\left(1-\lambda_{1}\right)\right] q_{t-1}++\frac{\theta_{1}}{\lambda_{2}} \sum_{j=0}^{\infty} \lambda_{2}^{-j} \lambda p_{t+j}
$$

where $\theta_{1}=\left[\beta v_{s s}+\beta v_{q q}\right]^{-1}$ and $\theta=-\theta_{1} v_{q s}$.

\section{Proof:}

Set $\delta=1$ in Equation (14) and use the fact that $s_{t+1}=q_{t}$.

In this special case, we have the model of Becker et al [5]. However, now we can interpret the results for both habit formation and stock adjustment. If the model exhibits habit formation, then $v_{q s}>0$ and the parameter $\theta>0$. Because the characteristic root, $0<\lambda_{1}<1$, (Proposition 1) it follows that lagged quantity has a positive effect on current quantity. When the parameter $\theta<0$, durable goods behavior predominates and the effect of lagged quantity on current quantity is negative because the characteristic root lies between zero and -1 (Proposition 1). We can also infer from Equation (9) that the model could also be represented as follows:

\section{Proposition 5.}

When the depreciation rate $\delta=1$, Equation (9) becomes

$$
q_{t}=\theta q_{t-1}+\beta \theta q_{t+1}+\theta_{1} \lambda p_{t}
$$

\section{Proof:}

Set $\delta=1$ in Equation (9) and we immediately obtain the result.

Therefore, we see directly how the model becomes identical to that of Becker et al [5], but as in Proposition 4 the parameter $\theta$ could be positive or negative to reflect either habit formation or durable good behavior.

\section{Discussion}

The intertemporal state adjustment model, which is forward looking, produces a much different specification of demand than the static, myopic model. In particular, the intertemporal demand model, Equation (14), from Proposition 2 shows 
that demand depends on future expected prices, the user cost of capital, and beginning-of-the period state level. In contrast, the static model, Equation (15), only depends on current period price and the beginning-of-the period state level. Therefore, in contrast to the myopic model, the intertemporal model accounts for the speculative motive in stock holding.

Long-run effects of the intertemporal state adjustment model can be computed either using Equation (11) with Equation (14), or directly using (9) and (14). From Equation (9), the long-run price derivative of the state variable is

$$
\frac{\partial s^{*}}{\partial p^{*}}=\frac{\lambda[1-\beta(1-\delta)] \theta_{1}}{[1-\theta(1+\beta)]}
$$

where asterisks denote long-run steady-state levels. In contrast, the short-run effect, with steady-state price changes, is just the numerator of (18). This means, as is the case with myopic model, long-run effects exceed (are less than) shortrun effects as habit formation (inventory) behavior dominates. That is, when $\theta>0$, long-run price effects are larger in absolute value than short-run price effects; when $\theta<0$, long-run price effects are smaller in absolute value than shortrun price effects.

An alternative representation of the intertemporal state adjustment model that may also be more useful for econometric analysis can be obtained by multiplying both sides of Equation (9) by $[1-(1-\delta) L]$ and substituting for $q_{t}$ from Equation (5) to obtain:

$$
\begin{aligned}
q_{t}= & \theta q_{t-1}+\beta \theta q_{t+1}+\theta_{1}\left[\lambda p_{t}-\beta(1-\delta) \lambda p_{t+1}\right] \\
& -(1-\delta) \theta_{1}\left[\lambda p_{t-1}-\beta(1-\delta) \lambda p_{t}\right]
\end{aligned}
$$

Long-run price derivatives can be computed from Equation (19) directly

$$
\frac{\partial q^{*}}{\partial p^{*}}=\frac{\lambda[1-(1-\delta)][1-\beta(1-\delta)] \theta_{1}}{[1-\theta(1+\beta)]}
$$

As in the case of the state variable, Equation (16), short-run effects will be larger (smaller) as the parameter $\theta$ is larger (smaller) than zero.

A full discussion of econometric strategies for estimating the intertemporal state adjustment model (19) is beyond the scope of this paper. However, it should be clear that the approach of Becker et al [5] is still applicable given values for $\beta$ and $\delta$, for then $\left[\lambda p_{t}-\beta(1-\delta) \lambda p_{t+1}\right],\left[\lambda p_{t-1}-\beta(1-\delta) \lambda p_{t}\right]$, and $\left[\lambda p_{t+1}-\beta(1-\delta) \lambda p_{t+2}\right]$ could be used as instruments for $q_{t}, q_{t-1}$, and $q_{t+1}$. See Arellano [7] for alternative approaches to selecting instrumental variables.

\section{Conclusion}

In contrast to the myopic state adjustment model, the intertemporal state adjustment model produces a forward-looking demand specification. Demand for the good in question can be characterized by Equation (10), Equation (14), or Equation (19). As shown in Equation (10), the static state adjustment model 
should be extended to include end-of-the period state variable and the price variable should be the user-cost variable, which includes the impact of both current and future (expected) price on demand. Equation (14) is the solution to this equation, expressing demand as a function of future expected user-cost variables on demand, conditioned on the beginning-of-the period state variable. Equation (19) shows that the demand equation of Becker et al. [5] needs to be extended to include both current and lagged user-cost variables. Estimation is feasible for such a model but more complicated than myopic state adjustment model. As in the myopic state adjustment model, the intertemporal model has the advantage to distinguish habit formation from stock adjustment such as might arise from inventory holding. The intertemporal state adjustment model properly accounts for the speculative motive and other forward looking behavior for inventory holding which are absent in the myopic state adjustment model.

\section{Acknowledgements}

Research supported in part by the North Carolina Agricultural Research Service, Raleigh, North Carolina 27695.

\section{References}

[1] Hendel, I. and Nevo, A. (2006) Measuring the Implications of Sales and Consumer Inventory Behavior. Econometrica, 74, 1637-1673. https://doi.org/10.1111/j.1468-0262.2006.00721.x

[2] Houthakker, H. and Taylor, L. (1970) Consumer Demand in the United States 1929-1970. Harvard University, Cambridge.

[3] Phlips, L. (1983) Applied Consumption Analysis. North Holland Publishing Co., Amsterdam, 168-175.

[4] Chaloupka, F. (1991) Rational Addictive Behavior and Cigarette Smoking. Journal of Political Economy, 99, 722-742. https://doi.org/10.1086/261776

[5] Becker, G., Grossman, M. and Murphy, K. (1994) An Empirical Analysis of Cigarette Addiction. American Economic Review, 84, 396-418.

[6] Sargent, T. (1979) Macroeconomic Theory. Academic Press, New York, 195-200.

[7] Arallano, M. (2003) Panel Data Econometrics. Oxford University Press, New York. https://doi.org/10.1093/0199245282.001.0001 
Submit or recommend next manuscript to SCIRP and we will provide best service for you:

Accepting pre-submission inquiries through Email, Facebook, LinkedIn, Twitter, etc. A wide selection of journals (inclusive of 9 subjects, more than 200 journals)

Providing 24-hour high-quality service

User-friendly online submission system

Fair and swift peer-review system

Efficient typesetting and proofreading procedure

Display of the result of downloads and visits, as well as the number of cited articles Maximum dissemination of your research work

Submit your manuscript at: http://papersubmission.scirp.org/

Or contact tel@scirp.org 